\title{
Accessibility of Cysteines in the Native Bovine Rod cGMP-Gated Channel
}

\author{
Paul J. Bauer*,‡ and Eberhard Krause ${ }^{\S}$ \\ Institute of Biological Information Processing, Research Center, D-52425 Juelich, Germany, and \\ Institute of Molecular Pharmacology, Campus Berlin Buch, D-13125 Berlin-Buch, Germany
}

Received October 1, 2004; Revised Manuscript Received November 20, 2004

\begin{abstract}
Cyclic nucleotide-gated channels of photoreceptors and olfactory sensory neurons are tetramers consisting of A and B subunits. Here, the accessibility of the cysteines of the bovine rod cyclic nucleotidegated channel is examined as a function of ligand binding. $N$-Ethylmaleimide-modified cysteines of both subunits were identified by mass spectrometry after trypsin digestion. In the absence of ligand, the intracellular carboxy-terminal cysteines of both subunits were accessible to $N$-ethylmaleimide. Activation of the channel abolished the accessibility of $\mathrm{Cys}^{505}$ of the A subunit and $\mathrm{Cys}^{1104}$ of the B subunit, with both being conserved cysteines of the cyclic nucleotide-binding sites. The cysteine of the pore loop of the B subunit was also found to be modified by this reagent in the absence of ligand. The total number of accessible cysteines of each subunit was determined by mass shifting upon modification with polyethylene glycol maleimide. In the absence of cyclic nucleotides, this hydrophilic reagent only weakly labeled cysteines of the A subunit but readily labeled at least three cysteines of the B subunit. Ligand binding exposed two cysteines of the A subunit and one cysteine of the B subunit to chemical modification. Double-modification experiments suggest that some of these cysteines are in or close to membranespanning domains. However, these cysteines could not yet be identified. Together, the cysteine accessibility of the native rod cyclic nucleotide-gated channel varies markedly upon ligand binding, thus indicating major structural rearrangements, which are of functional importance for channel activation.
\end{abstract}

Cyclic nucleotide-gated $(\mathrm{CNG})^{1}$ channels play a central role in the excitation of photoreceptors and olfactory cells $(1,2)$. In photoreceptors, light absorption activates the visual cascade resulting in hydrolysis of cGMP followed by closure of the CNG channels; thus, the steady depolarizing cation influx, existing in the dark, is shut down and the photoreceptor is hyperpolarized. In olfactory cells, stimulation by odorants results in activation of an adenylate cyclase, leading to an increase of cAMP and thus to activation of olfactory CNG channels.

In photoreceptors and olfactory cells, the CNG channels consist of tetramers of two different classes of subunits, lately designated CNGA and CNGB (3). Whereas the A subunits alone are assembled to functional CNG channels upon heterologous expression, this is not the case for the $\mathrm{B}$ subunits. However, the characteristics observed for the native CNG channels in rod photoreceptors or olfactory neurons are only observed upon heterologous coexpression of both $\mathrm{A}$ and $\mathrm{B}$ subunits $(4,5)$.

Previously, the stoichiometry of the A and B subunits of the $\mathrm{CNG}$ channels of the photoreceptor was proposed to be

* To whom correspondence should be addressed: Institute for Biological Information Processing (IBI), Research Center, D-52425 Juelich, Germany. Telephone: +2461-614352. Fax: +2461-614216. E-mail: p.j.bauer@fz-juelich.de.

Institute of Biological Information Processing.

$\S$ Institute of Molecular Pharmacology.

${ }_{1}^{1}$ Abbreviations: ROS, rod outer segment; NEM, $N$-ethylmaleimide; IAA, iodoacetamide; PEG, polyethylene glycol; PEG-MAL, polyethylene glycol maleimide; CNG, cyclic nucleotide gated; MALDI, matrixassisted laser desorption ionization; MS, mass spectrometry; TOF, timeof-flight; MS/MS, tandem mass spectrometry.
2A:2B $(6,7)$. Recently, however, considerable experimental evidence has been reported that suggests that the subunit stoichiometry of the CNG channels in both rod photoreceptors and olfactory cells is actually 3A:1B. Zheng et al. reported fluorescence resonance energy transfer (FRET) data suggesting that there is only one B subunit in the CNG channels of rod photoreceptors and olfactory neurons $(8,9)$. Zhong et al. demonstrated that the A subunit but not the B subunit of these CNG channels contains a characteristic carboxy-terminal leucine-zipper motif, which leads to selfassembly of a trimer $(10,11)$. However, while the $3 \mathrm{~A}: 1 \mathrm{~B}$ stoichiometry of rod CNG channels has recently received further experimental support, there is substantial evidence suggesting that the native cone $\mathrm{CNG}$ channel has a $2 \mathrm{~A}: 2 \mathrm{~B}$ subunit stoichiometry with like subunits arranged adjacent to each other (12).

For the rod CNG channel, Weitz et al. demonstrated directly by thiol-specific cross linking of the native channel in photoreceptor membranes that all of the adduct bands predicted for a channel with a 3A:1B but not for a channel with a 2A:2B stoichiometry were observed (13). To confine cross linking only to the $\mathrm{CNG}$ channels, the photoreceptor membranes were pretreated with $N$-ethylmaleimide (NEM), to block cysteines accessible to this reagent in the absence of nucleotides. Thiol-specific cross linking was then carried out in the presence of 8Br-cGMP, thus limiting cross linking to cysteines exposed upon activation of the channel. The fact that cross-link bands of both subunits were observed indicated that some cysteines of the CNG channel were only accessible in the presence of $8 \mathrm{Br}-\mathrm{cGMP}(13,14)$. 
Little is known about which cysteines of the CNG channel are accessible to thiol-specific reagents. The $\mathrm{A}$ and $\mathrm{B}$ subunits of the mature channel contain 6 and 15 cysteines, respectively. An additional cysteine at position 35 of the nascent channel is located in an amino acid sequence that is proteolytically removed in the mature CNG channel (15). The cysteines in the C-terminal domain of the A subunit were studied in some detail. A strong potentiation of the homomeric channel in the presence of thiol-specific reagents has been linked to the modification of $\mathrm{Cys}^{481}$ of the A subunit using site-directed mutagenesis $(16,17)$.

The number of accessible cysteines of a protein can directly be determined by thiol-specific mass tagging using polyethylene glycol activated with a maleimidyl group (PEGMAL). This method was recently introduced to probe cysteines in potassium channels and has been termed pegylation (18). Moreover, valuable supplementary information about specific cysteine residues is obtained by mass spectrometry (MS), which has become a method of choice for the characterization of post-translational modifications of proteins. Peptide mass fingerprinting by matrix-assisted laser desorption ionization (MALDI)-MS (19) and sequencing by tandem mass spectrometry (MS/MS) (20) provide accurate masses of peptides and fragment ions of selected peptides, respectively, which can be used for identification of proteins and unambiguous determination of modified sites in proteins $(21,22)$. Alkylation of cysteines has been shown to be useful for protection of reactive thiols prior to MS or as a tool for the identification of cysteine-containing peptides (23). Modification with NEM in conjunction with MS analysis was utilized to monitor accessible cysteines $(24,25)$.

In this paper, both pegylation and MS have been applied to the native rod $\mathrm{CNG}$ channel to examine which cysteines are amenable to chemical modification. The results indicate that the accessibility of some cysteines changes distinctly with the state of channel activation, suggesting that major structural changes of the conformation of the CNG channel occur upon activation.

\section{EXPERIMENTAL PROCEDURES}

Cysteine Modification of Rod Outer Segments (ROS) Membranes. ROS were prepared from bovine retinas, as described (14). Aliquots of purified ROS containing 5 or 10 $\mathrm{mg}$ of rhodopsin were stored in $600 \mathrm{mM}$ sucrose at $-80^{\circ} \mathrm{C}$ until use [buffer: $10 \mathrm{mM} N$-2-hydroxyethylpiperazine- $N^{\prime}$ 2-ethanesulfonic acid (HEPES), adjusted to $\mathrm{pH} 7.0$ with $\mathrm{KOH}, 300 \mathrm{mM} \mathrm{KCl}, 1 \mathrm{mM} \mathrm{MgCl}, 0.5 \mathrm{mM} \mathrm{CaCl}_{2}, 0.1 \mathrm{mM}$ ethylenediaminetetraacetic acid (EDTA), and $1 \mathrm{mM}$ dithiothreitol (DTT)].

To avoid bleaching of rhodopsin, protein modification was always carried out in dim red light. ROS membranes were prepared by hypotonic lysis of purified ROS by washing twice in $0.5 \mathrm{mM}$ Tris, $0.5 \mathrm{mM}$ HEPES, and $1 \mathrm{mM}$ EDTA followed by centrifugation in a Sorvall centrifuge, rotor SA300 at $22000 \mathrm{rpm}$ for $30 \mathrm{~min}$ at $4{ }^{\circ} \mathrm{C}$ to remove cytoplasmic proteins. The pellet was resuspended in $\mathrm{Na}-$ HEPES (10 mM HEPES/NaOH, $100 \mathrm{mM} \mathrm{NaCl}$, and $1 \mathrm{mM}$ EDTA) and $0.5 \mathrm{mM}$ DTT, and the following protease inhibitors were added: $5 \mu \mathrm{g} / \mathrm{mL}$ aprotinin, $5 \mu \mathrm{g} / \mathrm{mL}$ leupeptin, $2.2 \mu \mathrm{g} / \mathrm{mL}$ trans-epoxysuccinyl-L-leucylamido(4-guanidino)butane. The membranes were modified with 2 or 10
$\mathrm{mM}$ NEM in either the absence or presence of $8 \mathrm{Br}-\mathrm{cGMP}$, as indicated, by adding a freshly prepared $500 \mathrm{mM}$ stock solution of NEM in dimethylsulfoxide. The incubation time was $1 \mathrm{~h}$ at 25 or $37^{\circ} \mathrm{C}$, as indicated, and the reaction was stopped by adding excess DTT. PEG of 5 or $20 \mathrm{kDa}$ containing a single maleimidyl residue (PEG-MAL) was purchased from Nektar (Huntsville, AL). Pegylation was started by adding to the suspension the same volume of a freshly prepared stock solution of PEG-MAL in Na-HEPES, thus resulting in a final PEG-MAL concentration of half of the stock solution; the reaction was terminated after the indicated times with excess DTT.

Purification of the NEM-Modified CNG Channel. Purification of the CNG channel from NEM-modified ROS membranes was not feasible by calmodulin-affinity chromatography (26), indicating that the calmodulin-binding affinity was largely abated. A previously reported purification procedure (27) was also not possible, because the affinity gel AF Red Fractogel TSK is no longer commercially available. Therefore, we developed an alternative affinity chromatography procedure to purify the CNG channel, which works also for the NEM-modified CNG channel and which is based on Red Sepharose CL-6B (Amersham), where the triazine dye Procion Red HE-3B has been covalently bound to sepharose.

ROS membranes containing $20 \mathrm{mg}$ of rhodopsin were solubilized in $45 \mathrm{~mL}$ of $20 \mathrm{mM}$ CHAPS in buffer A (10 $\mathrm{mM}$ HEPES/NaOH at $\mathrm{pH} 7.4,150 \mathrm{mM} \mathrm{NaCl}, 10 \mathrm{mM} \mathrm{CaCl}_{2}$, $1 \mathrm{mM}$ EDTA, $1 \mathrm{mM}$ DTT, and $20 \mathrm{mM}$ CHAPS). The abovementioned protease inhibitors were present in all buffers. After solubilization by shaking for $1 \mathrm{~h}$ at room temperature, the solution was centrifuged for $30 \mathrm{~min}$ at $67500 \mathrm{~g}$ at $4{ }^{\circ} \mathrm{C}$ in a Sorvall centrifuge. The supernatant was loaded onto a $3 \mathrm{~mL}$ (diethylamino)ethyl (DEAE) cellulose column, and the flux was adjusted to $0.5 \mathrm{~mL} / \mathrm{min}$. The nonbound fraction was discarded, and the column was rinsed with buffer A for $1 \mathrm{~h}$. The bound fraction was eluted with buffer B $(10 \mathrm{mM}$ HEPES/NaOH at pH 7.4, $1000 \mathrm{mM} \mathrm{NaCl}, 10 \mathrm{mM} \mathrm{CaCl}_{2}, 1$ $\mathrm{mM}$ DTT, and $20 \mathrm{mM}$ CHAPS). This fraction was kept for $1 \mathrm{~h}$ at $4{ }^{\circ} \mathrm{C}$ to promote dissociation of the CNG channel and $\mathrm{Na} / \mathrm{Ca}, \mathrm{K}$ exchanger (14). Then, the buffer $\mathrm{B}$ was changed to buffer C (10 mM HEPES/NaOH at pH 7.4, $100 \mathrm{mM} \mathrm{NaCl}$, $10 \mathrm{mM} \mathrm{CaCl} 2,1 \mathrm{mM}$ DTT, and $20 \mathrm{mM}$ CHAPS) using a Sephadex G-25 column (PD-10, Amersham) and loaded on a $6 \mathrm{~mL}$ Red Sepharose Cl-6B column by cycling the solution for $1 \mathrm{~h}$ at $0.5 \mathrm{~mL} / \mathrm{min}$. The nonbound fraction was discarded, and the column was rinsed for $30 \mathrm{~min}$ with buffer $\mathrm{C}$. The bound fraction, containing the purified channel, was eluted with buffer D (10 mM HEPES/ $\mathrm{NaOH}$ at $\mathrm{pH} 7.4,750 \mathrm{mM}$ $\mathrm{NaCl}, 0 \mathrm{CaCl}_{2}, 1 \mathrm{mM}$ EDTA, $1 \mathrm{mM}$ DTT, and $20 \mathrm{mM}$ CHAPS). The buffer was changed over a Sephadex G-25 column to buffer $\mathrm{E}(10 \mathrm{mM}$ Tris/ $\mathrm{HCl}$ at $\mathrm{pH} 7.6,100 \mathrm{mM}$ $\mathrm{NaCl}, 1 \mathrm{mM}$ DTT, and $10 \mathrm{mM}$ CHAPS) followed by reduction of the volume to about $70 \mu \mathrm{L}$ by centrifugal ultrafiltering using a Centricon 100 tube (Millipore). All procedures were carried out at $4{ }^{\circ} \mathrm{C}$, unless otherwise stated.

Electrophoresis and Immunoblotting. For immunoblotting, proteins were electrophoresed on a linear 3.5-7.5\% gradient polyacrylamide gel and blotted onto a PVDF membrane (Millipore), as described (28). The subunits of the purified CNG channel were separated on a $6 \%$ polyacrylamide constant gel and stained with Coomassie Blue before being 
excised for mass spectrometric analysis.

In-Gel Digestion. The excised protein bands were washed with $50 \%$ (v/v) acetonitrile in $25 \mathrm{mM}$ ammonium bicarbonate, shrunk by dehydration in acetonitrile, and dried in a vacuum centrifuge. The gel pieces were reswollen in $10 \mu \mathrm{L}$ of $5 \mathrm{mM}$ ammonium bicarbonate containing $300 \mathrm{ng}$ of trypsin (sequencing grade, Roche Diagnostics, Mannheim, Germany). After $15 \mathrm{~min}, 10 \mu \mathrm{L}$ of $5 \mathrm{mM}$ ammonium bicarbonate was added to keep the gel pieces wet during enzymatic cleavage $\left(37{ }^{\circ} \mathrm{C}\right.$, overnight $)$. To extract the peptides, $20 \mu \mathrm{L}$ of $0.5 \%(\mathrm{v} / \mathrm{v})$ trifluoroacetic acid (TFA) in acetonitrile was added, the samples were sonicated for $5 \mathrm{~min}$, and the separated liquid was taken to dryness under vacuum. For MALDI-MS measurements, the samples were redissolved in $10 \mu \mathrm{L}$ of $0.1 \%(\mathrm{v} / \mathrm{v})$ TFA and $5 \%(\mathrm{v} / \mathrm{v})$ acetonitrile in water. The peptides were purified using a $\mathrm{C} 18$ reversedphase minicolumn fitted into a micropipet tip (ZipTip C18, Millipore, Bedford, MA), prior to mass spectrometric analysis. The purification was carried out according to the manual of the manufacturer. Peptides were eluted from the ZipTips with $2.5 \mu \mathrm{L}$ of $60 \%$ (v/v) acetonitrile and $0.3 \%(\mathrm{v} /$ v) TFA in water. For MS/MS, the samples were reconstituted in $5 \mu \mathrm{L}$ of $0.1 \%(\mathrm{v} / \mathrm{v})$ TFA and $6 \%(\mathrm{v} / \mathrm{v})$ acetonitrile in water.

Reduction of Disulfides and Alkylation. The excised protein bands were washed, shrunk, and dried in a vacuum centrifuge as described above. Disulfide bonds were reduced by incubation with $70 \mu \mathrm{L}$ of $10 \mathrm{mM}$ DTT in $25 \mathrm{mM}$ ammonium bicarbonate for $45 \mathrm{~min}$ at $55^{\circ} \mathrm{C}$. Alkylation was performed by replacing the DTT solution with $70 \mu \mathrm{L}$ of $55 \mathrm{mM}$ iodoacetamide in $25 \mathrm{mM}$ ammonium bicarbonate. After incubation for $20 \mathrm{~min}$ at $25^{\circ} \mathrm{C}$ in the dark, the gel pieces were washed with $50 \%(\mathrm{v} / \mathrm{v})$ acetonitrile in $25 \mathrm{mM}$ ammonium bicarbonate, shrunk by dehydration in acetonitrile, and dried in a vacuum centrifuge.

MALDI-MS. MALDI-MS measurements were performed on a Voyager-DE STR BioSpectrometry Workstation MALDI-time-of-flight (TOF) mass spectrometer (Perseptive Biosystems, Inc., Framingham, MA). A total of $1 \mu \mathrm{L}$ of the peptide solution was mixed with $1 \mu \mathrm{L}$ of $\alpha$-cyano-4hydroxycinnamic acid matrix solution consisting of $10 \mathrm{mg}$ of matrix dissolved in $1 \mathrm{~mL}$ of $0.3 \%$ TFA in acetonitrilewater $(1: 1, \mathrm{v} / \mathrm{v})$. From the resulting mixture, $1 \mu \mathrm{L}$ was applied to the sample plate. Samples were air-dried at ambient temperature $\left(24^{\circ} \mathrm{C}\right)$. Measurements were performed in the reflection mode at an acceleration voltage of $20 \mathrm{kV}, 70 \%$ grid voltage, and a delay of $200 \mathrm{~ns}$. Each spectrum obtained was the mean of 256 laser shots. Mass spectra were calibrated using autolytic fragments of trypsin as internal standards. Proteins were identified by searching the NCBI database using MS-Fit (http://prospector.ucsf.edu). The parameters for the search were as follows: The oxidation of methionine were considered as partial modifications. The maximum number of missed tryptic cleavages was 1 . The monoisotopic masses were considered, and the mass tolerance was set to 0.05 Da. Peptides from the cGMP-gated channel A subunit (SwissProt Q00194) and CNG-4 (SwissProt Q28181) covered 38 and $34 \%$ of the protein, respectively. FindMod (http://www.expasy.org/tools/findmod/) was used to find Cys-modified peptides.

MS/MS Analysis. MS/MS experiments were performed on a quadrupole orthogonal acceleration TOF mass spectrometer Q-Tof Ultima (Micromass, Manchester, U.K.) equipped with a Z-spray nanoelectrospray source. A Micromass CapLC liquid chromatography system was used to deliver the peptide solution to the electrospray source. A total of $5 \mu \mathrm{L}$ of the sample was injected using $0.2 \%$ formic acid (FA) in water at a flow rate of $20 \mu \mathrm{L} / \mathrm{min}$ (eluent $\mathrm{C}$ ) and concentrated on a precolumn (PepMap C18, $5 \mu \mathrm{m}, 100 \AA$ A, $5 \mathrm{~mm} \times 300 \mu \mathrm{m}$ inside diameter, LC Packings, Dionex, Idstein, Germany). Peptides were eluted onto an analytical column (PepMap C18, $3 \mu \mathrm{m}, 100 \AA, 150 \mathrm{~mm} \times 75 \mu \mathrm{m}$ inside diameter, LC Packings), and separations were performed at an eluent flow rate of $200 \mathrm{~nL} / \mathrm{min}$. Mobile phase A was $0.1 \% \mathrm{FA}(\mathrm{v} / \mathrm{v})$ in acetonitrile-water $(5: 95, \mathrm{v} / \mathrm{v})$, and $\mathrm{B}$ was $0.1 \% \mathrm{FA}$ in acetonitrile-water $(8: 2, \mathrm{v} / \mathrm{v})$. Runs were performed using a gradient of $10-65 \% \mathrm{~B}$ in $60 \mathrm{~min}$. The mass spectrometer was operated in the positive ion mode using PicoTip spray capillaries (New Objective, Woburn, MA). To perform MS/ MS experiments, automatic function switching (survey scanning) was employed. The collision gas was argon at a pressure of $6.0 \times 10^{-5}$ millibar. The processed MS/MS spectra (MassLynx version 4.0 software) were compared with the theoretical fragment ions of tryptic peptides of CNGA1 and CNGB1.

\section{RESULTS}

Cysteines are sensitive reporters of structural changes of the CNG channel upon activation; certain cysteine residues are only accessible to thiol-specific reagents after ligand binding and are then available for cross linking of the individual subunits $(13,14)$. However, little is known about the accessibility of cysteine residues in the native $\mathrm{CNG}$ channel. In the first part, we examine the accessibility to NEM of the C-terminal cysteines of both channel subunits by MALDI-MS of the tryptic peptides. In the second part, the total number of cysteines accessible to modification will be determined by thiol-specific pegylation (18).

Purification and Digestion of NEM-Modified CNG Channel. The accessibility of cysteines of the bovine rod $\mathrm{CNG}$ channel to chemical reagents was probed by treating washed bovine ROS membranes with NEM. To ensure maximal modification, we used a high concentration of $10 \mathrm{mM}$ of this membrane-permeable reagent. Unfortunately, NEM modification of the $\mathrm{CNG}$ channel strongly abated the calmodulin affinity of the CNG channel, although the predicted calmodulin-binding sites of the B subunit do not contain cysteines (29). Presumably, loss of calmodulin binding is due to modification of one or more of the three cysteines located about 30 amino acids downstream of the first calmodulin-binding site $\left(\mathrm{Cys}^{741}, \mathrm{Cys}^{745}\right.$, and Cys $\left.{ }^{746}\right)$. Therefore, purification of the NEM-modified channel by calmodulin-affinity chromatography was not feasible.

To overcome this problem, we elaborated a two-step purification procedure using Red Sepharose CL-6B affinity chromatography (see the Experimental Procedures). The purified CNG channel was eluted at medium ionic strength in the absence of divalent ions (Figure 1). Purification of the CNG channel by this procedure was also feasible after NEM modification. In some experiments, little B subunit but no A subunit was eluted during the washing procedure (not shown). It should be noted in this context that the B subunit was significantly or even completely lost by the previously published procedure using AF Red Fractogel TSK affinity chromatography (27). 




FIGURE 1: Purification of the rod CNG channel. DEAE ionexchange chromatography followed by Red Sepharose CL-6B affinity chromatography was employed to purify the bovine rod CNG channel. The bound fraction (lane a) contained both the A and $\mathrm{B}$ subunits, and the nonbound fraction (lane b) contained mainly the $\mathrm{Na} / \mathrm{Ca}, \mathrm{K}$ exchanger. SDS-PAGE was carried out with a constant $6 \%$ polyacrylamide gel. (A) Coomassie-Blue-stained gel. (B) Western blot labeled with the monoclonal antibody PMc 2G11 against the A subunit. (C) Same blot reprobed with the monoclonal antibody PMe 5E11 against the B subunit. (D) Same blot reprobed with polyclonal antibodies against the $\mathrm{Na} / \mathrm{Ca}, \mathrm{K}$ exchanger.

NEM modification of the cysteines of washed ROS membranes was carried out in both the presence and absence of $8 \mathrm{Br}$-cGMP. In each instance, the channel was purified, the subunits were separated by sodium dodecyl sulfatepolyacrylamide gel electrophoresis (SDS-PAGE), and the Coomassie-stained protein bands were excised and used for in-gel digestion with trypsin. To detect free thiol groups, one sample was reduced with DTT and alkylated with iodoacetamide (IAA) before tryptic digestion was carried out.
MALDI-MS Analysis of Tryptic Peptides of the A Subunit. Complete digestion with trypsin should result in 79 and 120 peptides with molecular masses of up to 3943 and 13120 $\mathrm{Da}$ for the A and B subunits, respectively. The number of peptides observed is expected to be even higher because of incomplete digestion, which cannot be avoided. Peptides of molecular masses below about 3000 Da could be detected with sufficient sensitivity and resolution to allow an unambiguous identification of peptide masses. The cysteinecontaining tryptic peptides of the $\mathrm{C}$-terminal domain of the $\mathrm{A}$ and $\mathrm{B}$ subunits were in this range. NEM modification of a cysteine increased the molecular mass of the peptide containing this cysteine by $125 \mathrm{Da}$, and alkylation with iodoacetamide increased it by $57 \mathrm{Da}$.

The C-terminal cytoplasmic domain of the A subunit contains three cysteines, viz. $\mathrm{Cys}^{481}, \mathrm{Cys}^{505}$, and $\mathrm{Cys}^{573}$, which are located on different tryptic peptides with $\mathrm{m} / \mathrm{z}$ of 1733, 1611, and 1333, respectively. The cysteine of the peptide with $\mathrm{m} / z 1733$ was NEM-modified, because a peptide of $\mathrm{m} / \mathrm{z} 1858$ was clearly observed (Figure 2). This cysteine was modified by NEM in both the absence and presence of 8Br-cGMP (parts A and B of Figure 2).

The cysteine at position 505 of the A subunit contained in the peptide with $\mathrm{m} / \mathrm{z} 1611$ was also accessible to NEM resulting in a peptide with $\mathrm{m} / \mathrm{z} 1736$ (Figure 3A). In-gel modification with IAA of the A subunit, which was treated with NEM in the absence of $8 \mathrm{Br}-\mathrm{cGMP}$, yielded similar amounts of both NEM- and IAA-modified peptide indicating that the NEM modification was not complete. Surprisingly, NEM modification of Cys ${ }^{505}$ was never observed if the NEM treatment was carried out in the presence of $8 \mathrm{Br}$-cGMP (Figure 3B). In this case, in-gel reduction of the A subunit with DTT and modification of free cysteines with IAA confirmed that $\mathrm{Cys}^{505}$ was free and could be alkylated, resulting in a peptide with $\mathrm{m} / \mathrm{z} 1668$ (Tables 1 and 2). Considering that $\mathrm{Cys}^{505}$ is located in the cGMP-binding domain of the A subunit, these findings indicate that binding of cGMP led to a structural change, which entailed a loss of accessibility of this cysteine.

The tryptic peptide with $\mathrm{m} / \mathrm{z} 1333$ of the A subunit containing the $\mathrm{Cys}^{573}$ was found as an NEM-modified peptide with $m / z 1458$ (Tables 1 and 2). Most of this cysteine was observed in an incompletely cleaved 26 amino acid peptide $\left(\mathrm{S}^{565} \ldots \mathrm{C}^{573} \ldots \mathrm{K}^{590}\right)$, which was modified by NEM giving rise

\begin{tabular}{|c|c|c|c|c|c|}
\hline & \multirow{2}{*}{$\begin{array}{l}\text { peptide } \\
\text { number }\end{array}$} & \multicolumn{2}{|c|}{ NEM } & \multicolumn{2}{|c|}{ NEM + in-gel DTT/IAA } \\
\hline & & $\overline{\text { no cGMP }}$ & 8Br-cGMP & no cGMP & 8Br-cGMP \\
\hline \multicolumn{6}{|l|}{ A subunit (CNGA1) } \\
\hline $\mathrm{L}^{493} \ldots \mathrm{C}^{505} \mathrm{~K}^{506}$ & 2 & $\mathrm{C}_{\mathrm{NEM}}$ & & $\mathrm{C}_{\mathrm{NEM}}, \mathrm{C}_{\mathrm{CAM}}$ & $\mathrm{C}_{\mathrm{CAM}}$ \\
\hline $\mathrm{S}^{565} \ldots \mathrm{C}^{573} \mathrm{LSK}^{576}$ & 3 & $\mathrm{C}_{\mathrm{NEM}}$ & & $\mathrm{C}_{\mathrm{NEM}}$ & $\mathrm{C}_{\mathrm{NEM}}$ \\
\hline$S^{565} \ldots C^{573} \ldots K^{590}$ & 4 & $\mathrm{C}_{\mathrm{NEM}}$ & $\mathrm{C}_{\mathrm{NEM}}$ & & \\
\hline \multicolumn{6}{|l|}{ B subunit (CNGB1) } \\
\hline $\mathbf{C}^{949} \mathrm{YYWAVK}^{955}$ & 5 & $\mathrm{C}_{\mathrm{NEM}}$ & & $\mathrm{C}_{\mathrm{NEM}}$ & \\
\hline $\mathrm{V}^{1074} \ldots \mathrm{C}^{1080} \mathrm{DR}^{1082}$ & 6 & $\mathrm{C}_{\mathrm{NEM}}, \mathrm{C}_{\text {free }}$ & $\mathrm{C}_{\mathrm{NEM}}, \mathrm{C}_{\text {free }}$ & $\mathrm{C}_{\mathrm{NEM}}, \mathrm{C}_{\mathrm{CAM}}$ & $\mathrm{C}_{\mathrm{NEM}}, \mathrm{C}_{\mathrm{CAM}}$ \\
\hline 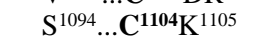 & 7 & $\mathrm{C}_{\mathrm{NEM}}, \mathrm{C}_{\text {free }}$ & $\mathrm{C}_{\text {free }}$ & $\mathrm{C}_{\mathrm{NEM}}$ & $\mathrm{C}_{\mathrm{CAM}}$ \\
\hline
\end{tabular}

${ }^{a}$ The CNG channel was modified in the ROS membrane with NEM either in the absence (columns marked no cGMP) or in the presence (columns marked 8Br-cGMP) and purified. After SDS-PAGE in a $6 \%$ polyacrylamide gel, the subunits were excised, digested with trypsin, and analyzed with MALDI-MS (columns headed NEM). Alternatively, the subunits were reduced and alkylated with IAA, to identify free cysteines (columns headed NEM + in-gel DTT/IAA), before tryptic digestion and MALDI-MS. The modification found by MS is indicated as a suffix, where CAM denotes the carboxyamidomethyl modification upon IAA treatment. 

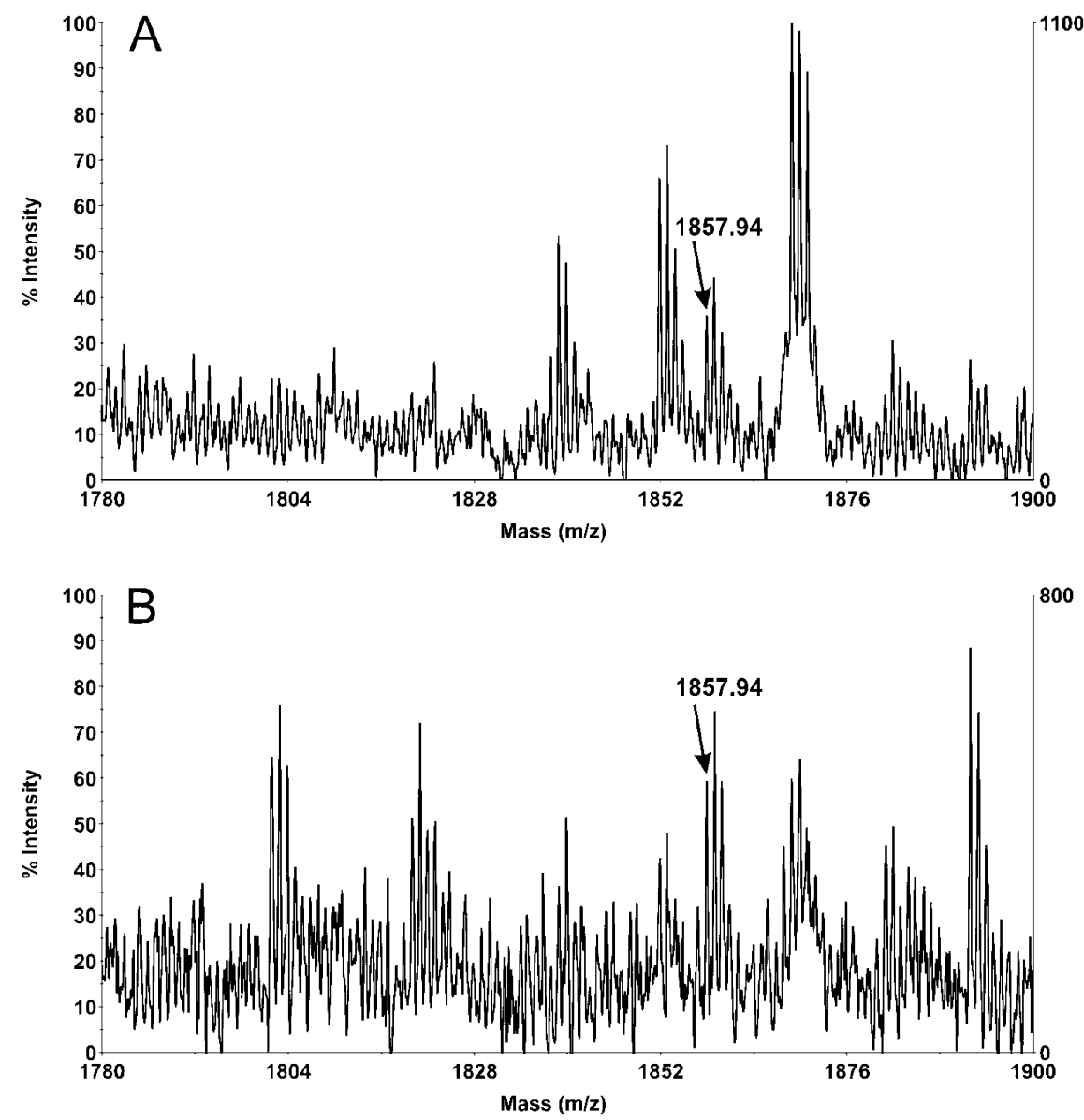

FIGURE 2: Mass spectrometric analysis of the A subunit of the CNG channel after NEM modification in the (A) absence and (B) presence of $8 \mathrm{Br}$-cGMP. The protein was in-gel-digested by trypsin, and the resulting peptides were analyzed by MALDI-MS. The monoisotopic mass peak with $\mathrm{m} / \mathrm{z}$ 1857.94, which corresponds to the NEM-modified sequence $\mathrm{I}^{477}$ FADC(NEM)EAGLLVELVLK ${ }^{492}$, was detected independently on the presence of the ligand.

to a peptide with $m / z$ 3049. There was no difference whether NEM modification was carried out in the presence or absence of 8Br-cGMP, suggesting that this cysteine was accessible to NEM modification irrespective of ligand binding.

MALDI-MS Analysis of Tryptic Peptides of the B Subunit. The three cysteines of the B subunit, which are located in the C-terminal domain, namely, $\mathrm{Cys}^{1010}{ }^{\mathrm{C}} \mathrm{Cys}^{1080}$, and $\mathrm{Cys}^{1104}$, are comprised in the tryptic peptides with $\mathrm{m} / \mathrm{z}$ 870, 1008, and 1400 , respectively. Unfortunately, peptides that contain the Cys ${ }^{1010}$ could not be detected. The peptide containing the Cys ${ }^{1080}$ was found to be partially NEM-modified regardless of the presence or absence of 8Br-cGMP during NEM treatment (Tables 1 and 2). In both instances, the IAA modification led to alkylation of free $\mathrm{Cys}^{1080}$, indicating that the NEM modification was incomplete.

The cysteine Cys ${ }^{1104}$ was found to be partially modified by NEM if NEM treatment was carried out in the absence of 8Br-cGMP (Tables 1 and 2). If NEM modification took place in the presence of $8 \mathrm{Br}$-cGMP, this cysteine was free and could be modified later in the polyacrylamide gel with IAA. Thus, this cysteine, which is located in the cGMPbinding domain, displays a similar accessibility to NEM as the analogous cysteine, $\mathrm{Cys}^{505}$, of the A subunit.

In contrast to the $\mathrm{A}$ subunit, the $\mathrm{B}$ subunit contains a cysteine in the pore loop region $\left(\mathrm{Cys}^{949}\right)$, which could also be identified in the NEM-modified form as a tryptic peptide with $\mathrm{m} / \mathrm{z} 1057$ (Tables 1 and 2). This peptide was only observed when the NEM treatment was carried out in the absence of $8 \mathrm{Br}-\mathrm{cGMP}$, suggesting that this cysteine is not accessible in the ligand-bound channel.

Changes of the cysteine accessibility upon ligand binding to the channel were of particular interest. As described above, such changes were found for $\mathrm{Cys}^{505}$ of the A subunit and $\mathrm{Cys}^{949}$ and $\mathrm{Cys}^{1104}$ of the B subunit. In each case, NEM modification was only observed for the nonliganded CNG channel. We applied MS/MS to confirm the amino acid sequences of the peptides containing those cysteines. Fragment ion spectra generated by collision-induced dissociation of the NEM-modified tryptic peptides $\mathrm{L}^{493} \ldots \mathrm{K}^{506}$ of the A subunit (Figure 4A) and the peptides $\mathrm{C}^{949} \ldots \mathrm{K}^{955}$ (Figure 4B) and $\mathrm{S}^{1094} \ldots \mathrm{K}^{1105}$ (Figure 4C) of the $\mathrm{B}$ subunit resulted in $\mathrm{N}$-terminal b-fragment ions and, in particular, in a series of C-terminal y-fragment ions, which unambiguously confirmed the identification of these peptides.

In summary, the MS data clearly show that, aside from Cys ${ }^{1010}$, which could not be unambiguously identified, all cysteine-holding peptides of the C-terminal domains of both channel subunits were accessible to NEM in the absence of $8 \mathrm{Br}$-cGMP. However, in the presence of $8 \mathrm{Br}$-cGMP, the $\mathrm{Cys}^{505}$ of the A subunit as well as the Cys ${ }^{949}$ and the Cys ${ }^{1104}$ of the B subunit were not detected in the NEM-modified form, indicating that these cysteines became inaccessible to NEM upon ligand binding. 

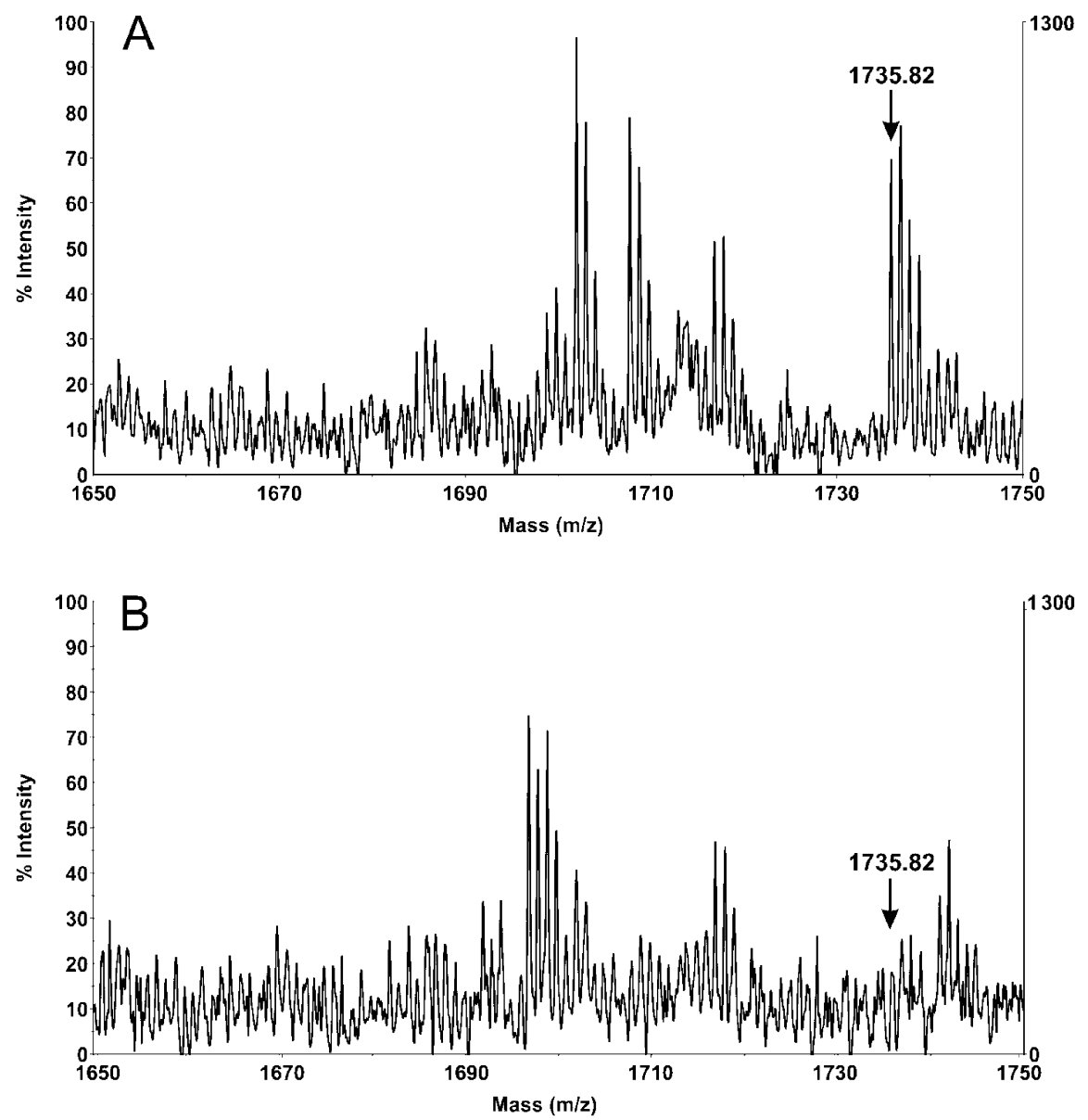

FIGURE 3: Mass spectrometric analysis of the A subunit of the CNG channel after NEM modification in the (A) absence and (B) presence of $8 \mathrm{Br}$-cGMP. The protein was in-gel-digested by trypsin, and the resulting peptides were analyzed by MALDI-MS. The monoisotopic mass peak with $m / z$ 1735.82, which corresponds to the NEM-modified sequence $\mathrm{L}^{493} \mathrm{QPQVYSPGDYIC}(\mathrm{NEM}) \mathrm{K}^{506}$, was detected only in the absence of $8 \mathrm{Br}-\mathrm{cGMP}$.

Table 2: Calculated and Observed Masses of Tryptic Cysteine-Containing Peptides, as Determined by MALDI-MS ${ }^{a}$

\begin{tabular}{cccc}
\hline peptide number & modification & {$[\mathrm{M}+\mathrm{H}]_{\text {calc }}^{+}$} & {$[\mathrm{M}+\mathrm{H}]_{\text {obs }}^{+}$} \\
\hline 1 & NEM & 1858.0029 & $1857.966 \pm 0.045(3)$ \\
2 & NEM & 1735.8359 & $1735.858 \pm 0.022(6)$ \\
2 & CAM & 1667.8097 & $1667.818 \pm 0.024(4)$ \\
3 & NEM & 1457.6980 & $1457.737 \pm 0.037(6)$ \\
4 & NEM & 3049.4055 & $3049.453 \pm 0.051(4)$ \\
5 & NEM & 1057.4811 & $1057.480 \pm 0.016(4)$ \\
6 & NEM & 1133.5407 & $1133.554 \pm 0.018(21)$ \\
6 & CAM & 1065.5146 & $1065.529 \pm 0.019(10)$ \\
6 & free & 1008.4931 & $1008.523 \pm 0.022(4)$ \\
7 & NEM & 1524.7402 & $1524.735 \pm 0.019(4)$ \\
7 & CAM & 1456.7140 & $1456.757 \pm 0.033(2)$ \\
7 & free & 1399.6926 & $1399.711 \pm 0.004(2)$ \\
\hline
\end{tabular}

${ }^{a}$ The numbering of the peptides refers to Table 1 . The error limits are standard deviations. The numbers of observation are given in parentheses.

Pegylation of the A Subunit of the cGMP-Gated Channel. Recently, PEG- MAL has been introduced as a useful tool to probe the accessibility of cysteines in peptides (18). This modification was termed pegylation and can be detected as a shift of the apparent molecular mass, depending on the number of cysteines modified. As opposed to NEM, PEG is membrane-impermeable, thus also conveying information on the sidedness of a cysteine.

In the absence of $8 \mathrm{Br}$-cGMP, pegylation of the cysteines with PEG-MAL of $5 \mathrm{kDa}$ for a prolonged period of time yielded a weak band of the A subunit, indicating that one cysteine was accessible to PEG-MAL (Figure 5). In contrast, after 1-2 $\mathrm{min}$, a strong band, a doublet band, and after prolonged exposure a triplet band were visible besides the monomer band in the presence of $8 \mathrm{Br}$-cGMP (arrows in Figure 5). We consistently observed that, whereas the lower band of the doublet is stronger after short exposure, the higher band became stronger after prolonged exposure. These findings indicated that at least two and possibly three cysteines of the A subunit became accessible to PEG-MAL upon ligand binding of the channel.

Remarkably, the shift of the apparent molecular mass was significantly higher than $5 \mathrm{kDa}$. The shift because of binding of a second PEG molecule was still much greater. This unequal band spacing prompted us to examine whether there is another PEG band in between; however, we did not find any indication for such a band. Therefore, the band shifts were not primarily due to the molecular masses of the PEG molecules but more likely to abnormal electrophoretic mobilities because of bulky PEG molecules; moreover, the band shifts presumably depended on the location of the modified cysteine on the A subunit.

Exposure to PEG-MAL was carried out with hypotonically washed ROS membranes, i.e., in a preparation that consisted predominantly of membrane vesicles (30). Therefore, some of the vesicles were inside-out and some were outside-out in orientation. This means that each channel was accessible 

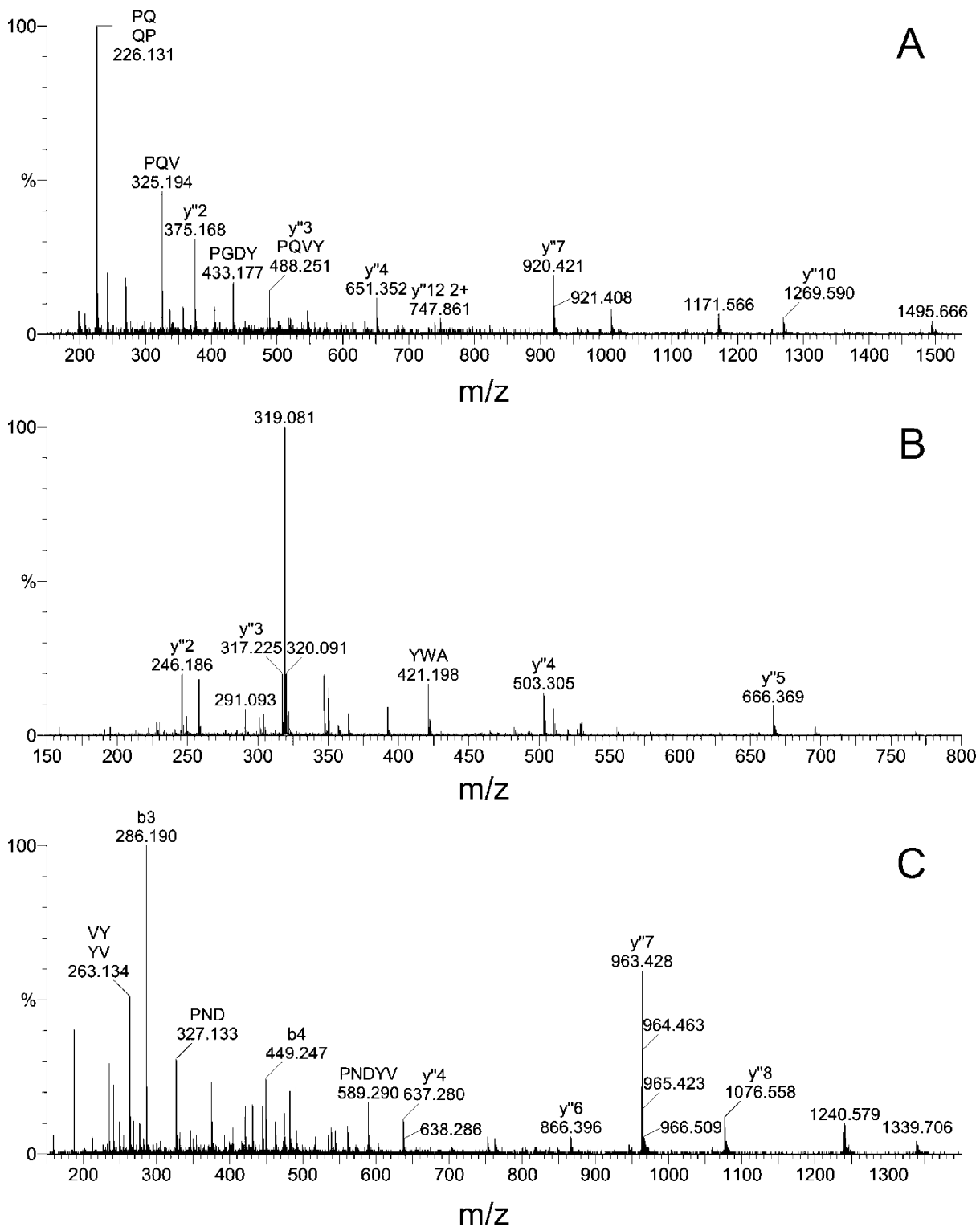

FIGURE 4: Tandem mass spectrometric analysis of NEM-modified tryptic fragments. Fragment ions (MS/MS spectra) of (A) $\mathrm{L}^{493} \mathrm{QPQVYSPGDYIC}(\mathrm{NEM}) \mathrm{K}^{506}$ of the A subunit with $\mathrm{m} / \mathrm{z}, 1735.84$, (B) C(NEM) ${ }^{949} \mathrm{YYWAVK}^{955}$ of the B subunit with $\mathrm{m} / \mathrm{z}$, 1057.48, and (C) $\mathrm{S}^{1094}$ VVYLPNDYVC(NEM)K $\mathrm{K}^{1105}$ of the B subunit with $\mathrm{m} / \mathrm{z}$. 1524.74. Relevant ions were labeled according to the accepted nomenclature (35). In particular, the y ions produced by consecutive fragmentation reactions of the doubly charged precursor ions $\mathrm{m} / \mathrm{z} 868.44,529.24$ and 762.88 confirm the presence of Cys(NEM) ${ }^{413}$ of the A subunit (A), Cys(NEM) ${ }^{949}(\mathrm{~B})$, and Cys(NEM) $)^{1104}$ of the B subunit $(\mathrm{C})$, respectively.

either only from the cytoplasmic or only from the extracellular membrane side. However, exposure of the ligandbound channel for more than 30 min to PEG-MAL resulted in almost complete pegylation of the A subunit (Figure 5). This finding suggests that cysteine residues from either membrane side were accessible to PEG modification. Therefore, two cysteines from one side and (at least) one cysteine from the other side were presumably modified. Together, these findings suggest that possibly three cysteines of the A subunit became accessible to PEG-MAL upon ligand binding.

Interestingly, the singly pegylated A subunit had a slightly higher electrophoretic mobility if pegylation occurred in the absence as compared to pegylation in the presence of $8 \mathrm{Br}$ cGMP (last two lanes of Figure 5). This observation suggested that different cysteines were pegylated, depending on ligand binding. In keeping with this inference, our previous studies indicated that cysteines of the rod CNG channel, which were accessible to modification in the presence of $8 \mathrm{Br}$ cGMP, were likely to be different from the cysteines accessible to NEM in the absence of ligand $(13,14)$.

To examine this hypothesis in more detail, we first blocked the cysteines with NEM in the absence of 8Br-cGMP, followed by a modification with PEG-MAL in the presence of $8 \mathrm{Br}$-cGMP. As shown in Figure 6, the outcome of this experiment was similar to the experiment with non-NEMtreated membranes: pegylation in the presence of $8 \mathrm{Br}$-cGMP yielded three additional bands indicating that up to three PEG molecules were bound per A subunit. In contrast to the above experiment, a distinct band of nonpegylated A subunit was always visible. This finding confirms that the PEG band observed in the absence of ligand (last lane of Figure 5) was due to a distinct cysteine because it could be removed by NEM pretreatment.

Pegylation of the B Subunit of the CGMP-Gated Channel. PEG-MAL of $20 \mathrm{kDa}$ was used to pegylate the B subunit 


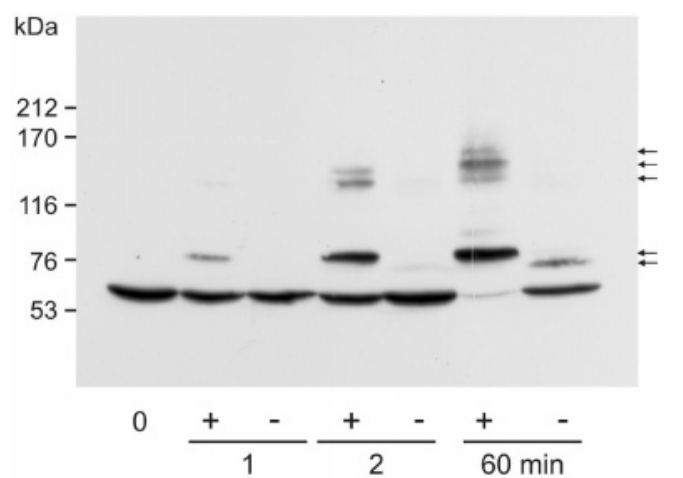

FIGURE 5: Thiol-specific pegylation of the rod CNG channel. Hypotonically washed ROS membranes were exposed at $37^{\circ} \mathrm{C}$ to $2 \mathrm{mM}$ PEG-MAL of $5 \mathrm{kDa}$, either in the presence of $200 \mu \mathrm{M} 8 \mathrm{Br}-$ cGMP (lanes labeled "+") or in the absence of ligand (lanes labeled "-_"). The first lane (labeled " 0 ") shows ROS membranes before modification. The reaction was stopped by addition of $140 \mathrm{mM}$ DTT after the indicated times. SDS-PAGE was a continuous 3.57.5\% polyacrylamide gel blotted onto a PVDF membrane. The blot was labeled with the monoclonal antibody PMc 2G11 against the A subunit of the bovine rod CNG channel. Arrows indicate PEGshifted bands.

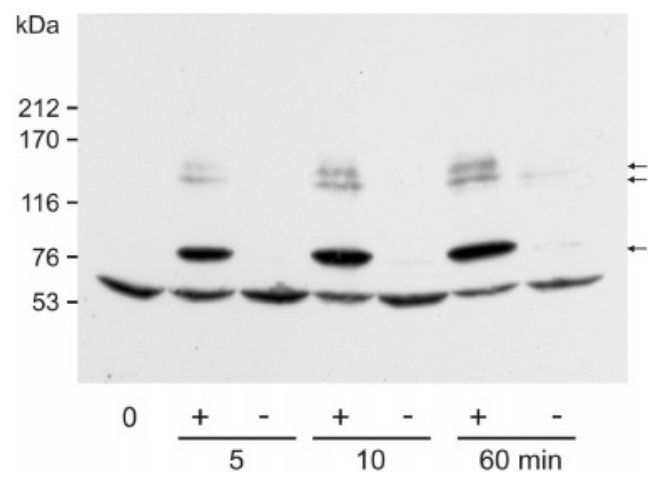

FIGURE 6: Thiol-specific pegylation of the NEM-modified rod CNG channel. ROS membranes were incubated in $2 \mathrm{mM}$ NEM at 25 ${ }^{\circ} \mathrm{C}$. The reaction was stopped after $15 \mathrm{~min}$ by addition of $5 \mathrm{mM}$ DTT. The membranes were washed twice with incubation buffer, resuspended, and exposed to $1 \mathrm{mM}$ PEG-MAL of $5 \mathrm{kDa}$ either in the presence of $125 \mu \mathrm{M} 8 \mathrm{Br}$-cGMP (lanes labeled "+") or in the absence of ligand (lanes labeled "-"). The reaction was stopped with 140 mM DTT after the indicated times. Lane labeled "0" was NEM-modified membranes before pegylation. SDS-PAGE, blot, and immunolabeling of the A subunit were the same as in Figure 5. Arrows indicate PEG-shifted bands.

because this subunit has a higher molecular mass than the A subunit. Pegylation was very fast, even at $4{ }^{\circ} \mathrm{C}$, resulting in three additional bands. Exposing the membranes to 500 $\mu \mathrm{M}$ PEG-MAL for only $15 \mathrm{~s}$ at $4{ }^{\circ} \mathrm{C}$ yielded two distinct PEG bands (Figure 7A). A third additional band developed in the next few minutes, and after exposure for $30 \mathrm{~min}$, two equally strong bands resulted, indicating that part of the $\mathrm{B}$ subunits bound two and a part bound three PEG molecules. A weak band corresponding to one bound PEG molecule was also visible after $30 \mathrm{~min}$, but the band of nonpegylated B subunit was almost absent (Figure 7B). There was no difference whether pegylation was carried out in the presence or absence of $8 \mathrm{Br}$-cGMP.

The fact that the band of the nonpegylated B subunit rapidly diminished upon pegylation indicated that most or all B-subunit molecules became pegylated. Recalling that pegylation was carried out with membrane vesicles containing inside-out and outside-out vesicles (see above), we
A

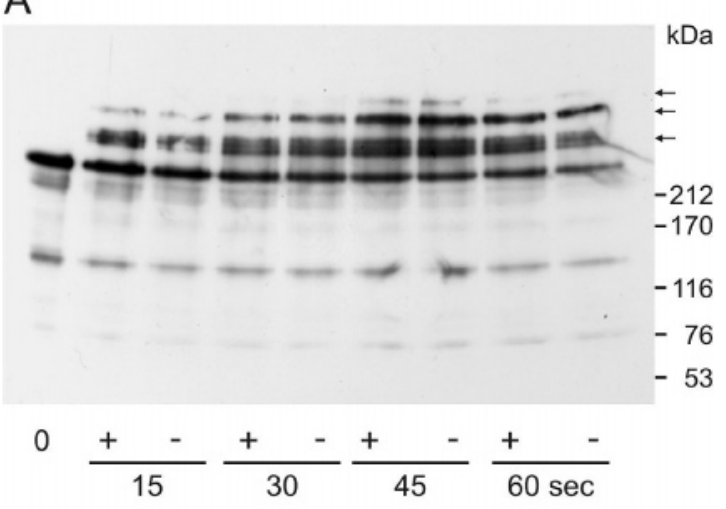

B

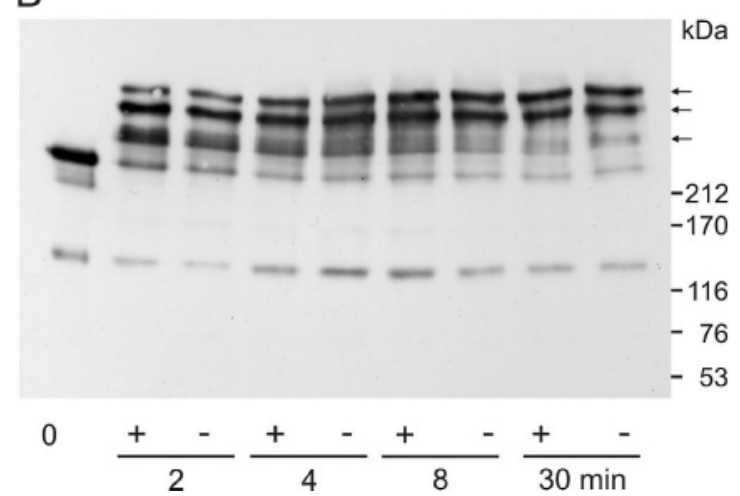

FIGURE 7: (A) Kinetics of pegylation of the $\mathrm{B}$ subunit of the $\mathrm{CNG}$ channel. Washed ROS membranes were modified at $4{ }^{\circ} \mathrm{C}$ with 500 $\mu \mathrm{M}$ PEG-MAL of $20 \mathrm{kDa}$ in the presence (lanes labeled "+") and absence (lanes labeled "-") of $125 \mu \mathrm{M} 8 \mathrm{Br}$-cGMP. Aliquots were taken after the indicated times and stopped with $140 \mu \mathrm{M}$ DTT. (B) Continuation of the experiment shown in A, except for the first lane. The first lane in both panels (labeled "0") is nonmodified membranes. SDS-PAGE was a continuous $3.5-7.5 \%$ polyacrylamide gel blotted onto a PVDF membrane. The blot was labeled with the monoclonal antibody PMe 5E11 against the B subunit of the bovine rod CNG channel. The arrows indicate the three PEGshifted bands.

presume that one part of the B subunit was pegylated from the cytoplasmic side and the other part from the extracellular side. This inference implies that a total of five cysteines of the B subunit was readily accessible to chemical modification.

In an attempt to probe the accessibility of the remaining cysteines of the B subunit, we blocked the readily accessible cysteines with NEM. After NEM modification, distinct pegylation of the B subunit in NEM-treated membranes was only discernible after more than $30 \mathrm{~min}$ of exposure to PEGMAL at $25^{\circ} \mathrm{C}$ (arrow in Figure 8). A single additional band eventually developed indicative for binding of one PEG molecule. Pegylation of the B subunit was clearly favored in the presence of $8 \mathrm{Br}-\mathrm{cGMP}$, indicating that binding of $8 \mathrm{Br}-$ cGMP increased the accessibility of one cysteine.

\section{DISCUSSION}

All six cysteines in the A subunit of the rod CNG channel (CNGA1) are conserved between human, bovine, and chicken photoreceptors, and except for $\mathrm{Cys}^{169}$ of CNGA1 (bovine), these cysteines are even conserved between the A subunits of rod and cone CNG channels in human and bovine retinas (CNGA3) $(31-33)$. Moreover, three of these six 


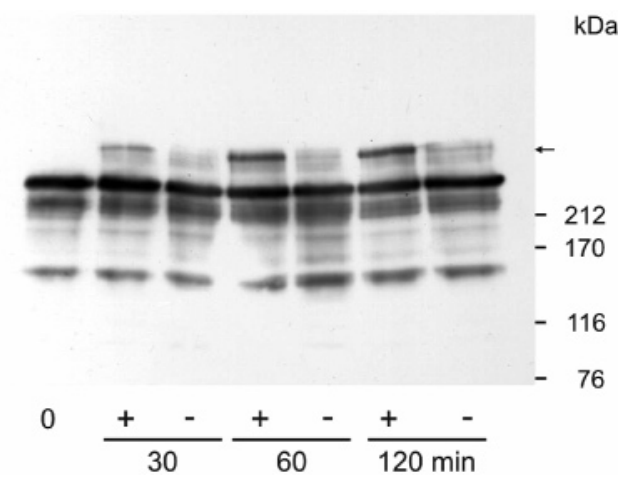

FIGURE 8: Prolonged exposure of NEM-modified ROS membranes to PEG-MAL. ROS membranes were modified at $25^{\circ} \mathrm{C}$ with 2 $\mathrm{mM}$ NEM in the absence of ligand. After termination of the reaction with $5 \mathrm{mM}$ DTT and removal of NEM, the membranes were exposed to $1000 \mu \mathrm{M}$ PEG-MAL of $20 \mathrm{kDa}$ in the presence (lanes labeled "+") and absence (lanes labeled "-") of $125 \mu \mathrm{M} \mathrm{8Br}$ cGMP. Control lane (labeled "0") was NEM-modified ROS membranes before pegylation. Aliquots were taken after the indicated times. Pegylation was stopped with $140 \mathrm{mM}$ DTT. SDSPAGE and blot were the same as in Figure 7. The B subunit was labeled with PMe 5E11. The arrow indicates a PEG-shifted band.

cysteines are conserved between CNGA1 and CNGB1, viz., $\mathrm{Cys}^{314}$ and $\mathrm{Cys}^{921}$ in the S5 transmembrane domain, Cys ${ }^{481}$ and $\mathrm{Cys}^{1080}$ in the linker domains between $\mathrm{S} 6$ and the CNGbinding site, and $\mathrm{Cys}^{505}$ and $\mathrm{Cys}^{1104}$ in the CNG-binding sites of A and B subunits, respectively (Figure 9).

We studied the cysteine accessibility of the native rod $\mathrm{CNG}$ channel in the absence and presence of the ligand $8 \mathrm{Br}$ cGMP. Different classes of cysteines were found: (a) cysteines that were accessible to thiol-specific reagents independent of ligand binding, (b) cysteines that were only accessible in the nonliganded state, (c) cysteines that were only accessible in the ligand-bound state, and (d) cysteines that were not accessible to chemical modification independent of the state of ligand binding. However, the latter class of cysteines was not investigated in any detail.

Several cysteines have been found to belong to class a comprising the cysteines that were modified by NEM in either state of ligand binding. MS revealed that the cysteines $\mathrm{Cys}^{481}$ of the A subunit and Cys ${ }^{1080}$ of the B subunit belonged to this class. This finding is in agreement with previous studies reporting evidence that, in heterologously expressed homomeric channels, consisting only of A subunits, the cysteine $\mathrm{Cys}^{481}$ was accessible to cysteine-modifying reagents $(16,17)$. Modification of $\mathrm{Cys}^{481}$ entailed a strong potentiation of the channel. The functional importance of the homologous Cys ${ }^{1080}$, which is in the linker region of the B subunit, has not yet been investigated.

The cysteine $\mathrm{Cys}^{573}$ of the A subunit was also accessible to NEM in either state of ligand binding. This cysteine is not conserved between A and B subunits. A distinct functional influence of this cysteine on the heterologously expressed channel was not observed (16).

Pegylation indicated that at least three and possibly even five cysteines (see the Results) were readily accessible in the B subunit, independent of ligand binding. Some of these cysteines may be those occurring in the glutamic-acid-rich protein (GARP) domain, which, in the cell, interacts with the peripherin- 2 oligomers in the rim region of the disc membranes (34). Unfortunately, these cysteines could not be identified by MS.

\section{CNGA1}

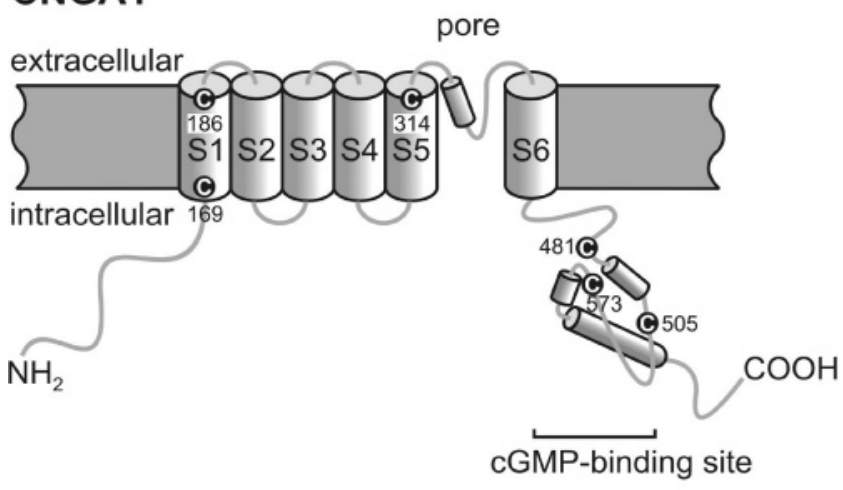

CNGB1

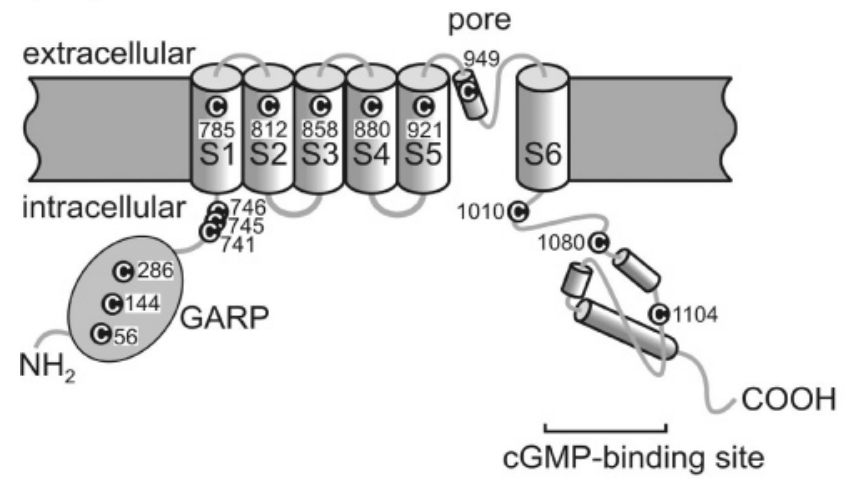

FIGURE 9: Membrane topology of the A and B subunits of the rod CNG channel. Except for the GARP domain at the $\mathrm{N}$ terminus of the B subunit, the topology of both subunits is similar. However, the B subunit contains 15 cysteines in contrast to the A subunit, which contains only 6 cysteines. Conserved cysteines include Cys ${ }^{314}$ and $\mathrm{Cys}^{921}, \mathrm{Cys}^{481}$ and $\mathrm{Cys}^{1080}$, and Cys ${ }^{505}$ and Cys ${ }^{1104}$ of A and B subunits, respectively. Predicted helical domains are indicated by tubes.

Of particular interest were cysteines that changed the accessibility upon binding of 8Br-cGMP because these cysteines are located in domains that undergo structural rearrangements. MS revealed that $\mathrm{Cys}^{505}$ of the A subunit and $\mathrm{Cys}^{1104}$ of the B subunit belong to this class. These cysteines are conserved in the so-called $\beta$ roll of the $\mathrm{A}$ and B subunit of the cyclic nucleotide-binding domain (1). The common feature of these cysteines was that they were all NEM-modified in the absence but not in the presence of $8 \mathrm{Br}$ cGMP. We confirmed for both $\mathrm{Cys}^{505}$ and Cys ${ }^{1104}$ by in-gel IAA modification that these cysteines were free after prolonged incubation in $10 \mathrm{mM} \mathrm{NEM}$ in the presence of 8Br-cGMP.

Working with the heterologously expressed homomeric CNG channel, Matulef et al. reported that ligand binding strongly reduced the reaction rate of modification of $\mathrm{Cys}^{505}$ with $500 \mu \mathrm{M}$ thimerosal (17); nevertheless, they observed a significant, though much slower rate of modification, although the concentration of the reagent was much smaller than in our experiment. In contrast, our data suggest that ligand binding resulted in a virtually complete occlusion of $\mathrm{Cys}^{505}$ and $\mathrm{Cys}^{1104}$ in the A and B subunits, respectively. We presume that this discrepancy may be due to subtle structural differences between the native and expressed homooligomeric CNG channel.

Another cysteine that was only found modified by NEM in the absence but not in the presence of ligand was Cys ${ }^{949}$ 
of the B subunit (Figure 9). Interestingly, this cysteine is located in the pore loop of the B subunit, indicating that this part of the protein experiences major structural changes upon channel activation. It is tempting to hypothesize that in both subunits this region is involved in the opening and closing mechanism of the channel. However, the pore loop of the A subunit does not contain a cysteine; therefore, no structural information about this domain was obtained in this study.

Cysteines that were only accessible in the presence of $8 \mathrm{Br}$ cGMP could not be identified by MALDI-MS, but robust evidence for this class of cysteines was obtained by pegylation, i.e., by modification with PEG-MAL. This is most evident for the A subunit, which only slowly reacted with PEG-MAL in the absence of ligand, whereas pegylation in the presence of $8 \mathrm{Br}-\mathrm{cGMP}$ was fast and efficient, resulting in at least two and possibly three distinct additional bands (arrows in Figure 5). Even after NEM treatment of ROS membranes, the A subunit could readily be pegylated in the presence of 8Br-cGMP (arrows in Figure 6) and, to some extent, one cysteine of the B subunit (arrow in Figure 8).

Previously, we reported that thiol-specific cross-linking of NEM-treated ROS membranes in the presence of $8 \mathrm{Br}$ cGMP resulted in a strong dimer band of the A subunit (14). Prolonged cross linking of these membranes in the presence of ligand resulted even in the appearance of all adduct bands consistent with a 3A:1B stoichiometry of the rod CNG channel (13). The inference that higher oligomers of the A subunit were generated by thiol-specific cross linking implied that more than one cysteine of the A subunit was exposed upon ligand binding; moreover, exposure of at least one cysteine of the B subunit upon ligand binding had to be assumed. We report here evidence indicating that, in fact, NEM-treated ROS membranes exposed upon ligand binding at least two cysteines of the A subunit to pegylation. Moreover, one cysteine of the B subunit became accessible to pegylation upon ligand binding, although at a much slower reaction rate than the cysteines of the A subunit (arrow in Figure 8). Thus, the above-stated necessary conditions for the formation of higher oligomers of CNG channel subunits upon cross linking are satisfied.

For successful cross linking, the cysteines exposed upon binding of 8Br-cGMP have to be adjacent to each other. Therefore, these cysteines convey information about the contacting protein domains of different subunits. The mass spectrometric data, reported here, indicate that all three cysteines of the $\mathrm{C}$-terminal domain of the A subunit are accessible to NEM in the absence of ligand. Therefore, the remaining cysteines, i.e., $\mathrm{Cys}^{169}$, Cys ${ }^{186}$, and $\mathrm{Cys}^{314}$ might be exposed upon ligand binding. However, two of these cysteines are in the predicted transmembrane domains S1 and S5, and only Cys ${ }^{186}$ is presumably in or close to the extracellular loop between S1 and S2. Although it is conceivable that cysteines in transmembrane domains are accessible to membrane-permeable reagents, one would not expect that these cysteines were also accessible to PEG-MAL unless ligand binding entailed a major structural change of this protein domain. Clearly, future work is necessary to identify the cysteines being cross-linked in the rod CNG channel.

This study suggests that changes of the accessibility of cysteines in highly conserved domains of both A and B subunits of the CNG channel are similar: the cysteines in the linker region were chemically accessible independent of ligand binding, whereas the conserved cysteines $\mathrm{Cys}^{505}$ and $\mathrm{Cys}^{1104}$ in the CNG binding sites of A and B subunits, respectively, were only accessible in the absence of ligand. The highly conserved pore loops of both subunits may also undergo similar structural changes upon ligand binding, as discussed above. Unfortunately, no information was obtained for the conserved cysteines in the S5 transmembrane domains of both subunits. Together, cysteines constitute important reporters of structural changes promising further insight into protein domains that undergo rearrangements of the $\mathrm{CNG}$ channel upon ligand binding.

\section{ACKNOWLEDGMENT}

We thank Dr. K. W. Koch, Dr. E. Nasi, and Dr. P. P. M. Schnetkamp for comments on the manuscript, Dr. R. S. Molday for a generous gift of the monoclonal antibodies PMc 2G11 and PMe 5E11 against bovine CNGA1 and CNGB1, respectively, and Dr. W. Bönigk for help with the sequence alignments. We also thank Mr. R. Esser and Mr. H. D. Grammig for technical help.

\section{REFERENCES}

1. Kaupp, U. B., and Seifert, R. (2002) Cyclic nucleotide-gated ion channels, Physiol. Rev. 82, 769-824.

2. Frings, S. (2001) Chemoelectrical signal transduction in olfactory sensory neurons of air-breathing vertebrates, Cell. Mol. Life Sci. $58,510-519$

3. Bradley, J., Frings, S., Yau, K.-W., and Reed, R. R. (2001) Nomenclature for ion channel subunits, Science 294, 2095-2096.

4. Körschen, H. G., Illing, M., Seifert, R., Sesti, F., Williams, A., Gotzes, S., Colville, C. A., Müller, F., Dosé, A., Godde, M., Molday, L. L., Kaupp, U. B., and Molday, R. S. (1995) A 240 $\mathrm{kDa}$ protein represents the complete $\beta$ subunit of the cyclic nucleotide-gated channel from rod photoreceptor, Neuron 15, 627-636.

5. Bönigk, W., Bradley, J., Müller, F., Sesti, F., Boekhoff, I., Ronnett, G. V., Kaupp, U. B., and Frings, S. (1999) The native rat olfactory cyclic nucleotide-gated channel is composed of three distinct subunits, J. Neurosci. 19, 5332-5347.

6. Shammat, I. M., and Gordon, S. E. (1999) Stoichiometry and arrangement of subunits in rod cyclic nucleotide-gated channels, Neuron 23, 809-819.

7. He, Y., Ruiz, M. L., and Karpen, J. W. (2000) Constraining the subunit order of rod cyclic nucleotide-gated channels reveals a diagonal arrangement of like subunits, Proc. Natl. Acad. Sci. U.S.A. 97, 895-900.

8. Zheng, J., Trudeau, M. C., and Zagotta, W. N. (2002) Rod cyclic nucleotide-gated channels have a stoichiometry of three CNGA1 subunits and one CNGB1 subunit, Neuron 36, 891-896.

9. Zheng, J., and Zagotta, W. N. (2004) Stoichiometry and assembly of olfactory cyclic nucleotide-gated channels, Neuron 42, 411421

10. Zhong, H., Molday, L. L., Molday, R. S., and Yau, K. W. (2002) The heteromeric cyclic nucleotide-gated channel adopts a 3A:1B stoichiometry, Nature 420, 193-198.

11. Zhong, H., Lai, J., and Yau, K. W. (2003) Selective heteromeric assembly of cyclic nucleotide-gated channels, Proc. Natl. Acad. Sci. U.S.A. 100, 5509-5513.

12. Peng, C., Rich, E. D., and Varnum, M. D. (2004) Subunit configuration of heteromeric cone cyclic nucleotide-gated channels, Neuron 42, 401-410.

13. Weitz, D., Ficek, N., Kremmer, E., Bauer, P. J., and Kaupp, U. B. (2002) Subunit stoichiometry of the CNG channel of rod photoreceptors, Neuron 36, 881-889.

14. Schwarzer, A., Schauf, H., and Bauer, P. J. (2000) Binding of the cGMP-gated channel to the $\mathrm{Na} / \mathrm{Ca}-\mathrm{K}$ exchanger in rod photoreceptors, J. Biol. Chem. 275, 13448-13454.

15. Molday, R. S., Molday, L. L., Dosé, A., Clark-Lewis, I., Illing, M., Cook, N. J., Eismann, E., and Kaupp, U. B. (1991) The cGMP- 
gated channel of the rod photoreceptor cell: Characterization and orientation of the amino terminus, J. Biol. Chem. 266, 2191721922.

16. Brown, R. L., Snow, S. D., and Haley, T. L. (1998) Movement of gating machinery during the activation of rod cyclic nucleotidegated channels, Biophys. J. 75, 825-833.

17. Matulef, K., Flynn, G. E., and Zagotta, W. N. (1999) Molecular rearrangements in the ligand-binding domain of cyclic nucleotidegated channels, Neuron 24, 443-452.

18. Lu, J., and Deutsch, C. (2001) Pegylation: A method for assessing topological accessibilities in Kv1.3, Biochemistry 40, 1328813301.

19. Henzel, W. J., Billeci, T. M., Stults, J. T., Wong, S. C., Grimley, C., and Watanabe, C. (1993) Identifying proteins from twodimensional gels by molecular mass searching of peptide fragments in protein sequence databases, Proc. Natl. Acad. Sci. U.S.A. 90, 5011-5015.

20. Eng, J. K., McCormack, A. L., and Yates, J. R. (1994) An approach to correlate tandem mass spectral data of peptides with amino acid sequences in a protein database, J. Am. Soc. Mass Spectrom. 5, 976-989.

21. Kleuss, C., and Krause, E. (2003) $\mathrm{G} \alpha(\mathrm{s})$ is palmitoylated at the N-terminal glycine, EMBO J. 22, 826-832.

22. Czupalla, C., Nurnberg, B., and Krause, E. (2003) Analysis of class I phosphoinositide 3-kinase autophosphorylation sites by mass spectrometry, Rapid Commun. Mass Spectrom. 17, 690696.

23. Sechi, S., and Chait, B. T. (1998) Modification of cysteine residues by alkylation. A tool in peptide mapping and protein identification, Anal. Chem. 70, 5150-5158.

24. Hubalek, F., Pohl, J., and Edmondson, D. E. (2003) Structural comparison of human monoamine oxidases $\mathrm{A}$ and B: Mass spectrometry monitoring of cysteine reactivities, J. Biol. Chem. 278, 28612-28618.

25. Whitelegge, J. P., le Coutre, J., Lee, J. C., Engel, C. K., Prive, G. G., Faull, K. F., and Kaback, H. R. (1999) Toward the bilayer proteome, electrospray ionization-mass spectrometry of large, intact transmembrane proteins, Proc. Natl. Acad. Sci. U.S.A. 96, $10695-10698$.

26. Hsu, Y.-T., and Molday, R. S. (1993) Modulation of the cGMP gated channel of rod photoreceptor cells by calmodulin, Nature $361,76-79$.
27. Cook, N. J., Hanke, W., and Kaupp, U. B. (1987) Identification, purification, and functional reconstitution of the cyclic GMPdependent channel from rod photoreceptors, Proc. Natl. Acad. Sci. U.S.A. $84,585-589$.

28. Schwarzer, A., Kim, T. S. Y., Hagen, V., Molday, R. S., and Bauer, P. J. (1997) The $\mathrm{Na} / \mathrm{Ca}-\mathrm{K}$ exchanger of rod photoreceptor exists as dimer in the plasma membrane, Biochemistry 36, 1366713676.

29. Weitz, D., Zoche, M., Müller, F., Beyermann, M., Körschen, H. G., Kaupp, U. B., and Koch, K.-W. (1998) Calmodulin controls the rod photoreceptor $\mathrm{CNG}$ channel through an unconventional binding site in the $\mathrm{N}$-terminus of the $\beta$-subunit, EMBO J. 17, 2273-2284.

30. Bauer, P. J. (1988) Evidence for two functionally different membrane fractions in bovine retinal rod outer segments, $J$. Physiol. 401, 309-327.

31. Bönigk, W., Altenhofen, W., Müller, F., Dosé, A., Illing, M., Molday, R. S., and Kaupp, U. B. (1993) Rod and cone photoreceptor cells express distinct genes for cGMP-gated channels, Neuron 10, 865-877.

32. Weyand, I., Godde, M., Frings, S., Weiner, J., Müller, F., Altenhofen, W., Hatt, H., and Kaupp, U. B. (1994) Cloning and functional expression of a cyclic-nucleotide-gated channel from mammalian sperm, Nature 368, 859-863.

33. Yu, W. P., Grunwald, M. E., and Yau, K. W. (1996) Molecular cloning, functional expression, and chromosomal localization of a human homolog of the cyclic nucleotide-gated ion channel of retinal cone photoreceptors, FEBS Lett. 393, 211-215.

34. Poetsch, A., Molday, L. L., and Molday, R. S. (2001) The cGMPgated channel and related glutamic acid rich proteins interact with peripherin-2 at the rim region of rod photoreceptor disc membranes, J. Biol. Chem. 276, 48009-48016.

35. Biemann, K., and Scoble, H. A. (1987) Characterization by tandem mass spectrometry of structural modifications in proteins, Science 237, 992-998.

BI0478749 